\title{
The reliability of surgeons to avoid traumatic insertion of dental implants into high-risk regions: a panoramic radiograph study
}

Firas A. Jamil ${ }^{1 *}$, Jamal A. Mohammed ${ }^{1}$, Thair A. Hasan ${ }^{1}$ and Mohammed G. Rzoqi ${ }^{2}$

\begin{abstract}
Background: The posterior regions of the jaws usually represent a significant risk for implant surgery. A non-valid assessment of the available bone height may lead to either perforation of the maxillary sinus floor or encroachment of the inferior alveolar nerve and consequently to implant failure. This study aimed to evaluate the reliability of surgeon's decision in appraising the appropriate implant length, in respect to vital anatomical structures, using panoramic radiographs.
\end{abstract}

Methods: Only implants that are inserted in relation to the maxillary sinus (MS) or the mandibular canal (MC) were enrolled (first premolars [1P], second premolars [2P], first molars [1M], and second molars [2M]). All preoperative panoramic radiographs were evaluated under standard conditions. The postoperative estimation (under/over) was determined depending on the available bone height ( $\mathrm{ABH}$ ) measured from the apical end of the implant to the floor of the MS and the roof of the MC using cone beam computed tomography (CBCT). Any complication or side effect that associated with overestimated implants insertion was recorded.

Results: The study sample included 73 patients (predominantly females) who had consecutively received 148 implants, of which 68 were inserted in the posterior maxilla and 80 in the posterior mandible. Underestimation was recorded in $93.2 \%$ of the measurements. The remaining bone height after implants insertion was $<2 \mathrm{~mm}$ in the majority of underestimated cases (73.9\%); they were significantly $(P<0.01)$ more than sites with remaining bone $\geq 2 \mathrm{~mm}$ (26.1\%). In the posterior mandible, overestimation was significantly higher than posterior maxilla. Five cases with transient paresthesia were reported in the mandibular overestimated implants.

Conclusions: This study specified that surgeon's choice of implants length, based on panoramic radiographs, was reliable regarding the incapability to insert implants with further length in the majority of underestimated cases, the low percent of overestimated measurements, and the minor associated complications.

Keywords: Panoramic radiographs, Dental implant, Maxillary sinus, Mandibular canal, Inferior alveolar nerve

\footnotetext{
* Correspondence: cbf_rm@yahoo.com

'Department of Oral \& Maxillofacial Surgery, Dental Teaching Hospital,

College of Dentistry, University of Baghdad, Bab-Almoadham, P.O.Box 1417, Baghdad, Iraq

Full list of author information is available at the end of the article
}

(c) The Author(s). 2020 Open Access This article is licensed under a Creative Commons Attribution 4.0 International License, which permits use, sharing, adaptation, distribution and reproduction in any medium or format, as long as you give appropriate credit to the original author(s) and the source, provide a link to the Creative Commons licence, and indicate if changes were made. The images or other third party material in this article are included in the article's Creative Commons licence, unless indicated otherwise in a credit line to the material. If material is not included in the article's Creative Commons licence and your intended use is not permitted by statutory regulation or exceeds the permitted use, you will need to obtain permission directly from the copyright holder. To view a copy of this licence, visit http://creativecommons.org/licenses/by/4.0/. The Creative Commons Public Domain Dedication waiver (http://creativecommons.org/publicdomain/zero/1.0/) applies to the data made available in this article, unless otherwise stated in a credit line to the data. 


\section{Background}

With the increasing number of dental practitioners, the prospect of having complications with implant surgery has expected to be increased. Surgical complications and accidents do occur [1] and may cause damage of vital anatomical structures [2]. They may also result in infection, inflammation, and ultimately the loss of implants $[3,4]$. Radiographic examination is an essential part of implant surgery and annually millions of these radiographs are taken for diagnosis and treatment [5]. To select an informative radiographic image, in addition to the patient's history and clinical investigations, one should consider the diagnostic quality, region of interest, radiation dose, the financial burden, and accessibility. Radiographic misinterpretation can result in serious complications. These complications can involve damage to adjacent teeth and/or encroachment of vital structures, including the maxillary sinus and/or inferior alveolar nerve (IAN). The risk of penetration into the maxillary sinus was reported, as implants could be accidentally displaced into the sinus cavity [6]. However, the posterior mandible comprised the highest risk area during implant surgery. The incidence of IAN injury has been increased during implant surgery due to the proximity to the mandibular canal and mental foramen. Dental implants were found to be the most common etiological risk factor (56.3\%) of nerve injury [7]. To avoid these complications, meticulous preoperative assessment is critical before insertion. Most implant surgeries can proceed uneventfully and fulfill functional and esthetic demands when proper diagnosis and treatment planning are implemented [8].

Prior to dental implant surgery, it is very important to assess the height of remaining alveolar bone in areas where implants are planned to be inserted, especially the posterior regions. The size of the maxillary sinus and its relationship with the upper teeth directly affect the surgical approach in this area [9]. Therefore, all oral surgeons have to be familiar with the anatomical limitations especially in the maxillary molar region. For these reasons, they should adopt appropriate surgical practices and inform patients about the possibility of any risk before operating [10]. In mandibular posterior teeth, the great majority present limited available bone between the root apex and the inferior alveolar canal (IAC). This stresses the need for careful attention during implant insertion in this area [8]. Otherwise, damage to the IAN may subsequently cause hemorrhage into the canal and/ or neurosensory disturbances $[7,11]$. This nerve was reported to be the most commonly injured nerve (64.4\%), followed by the lingual nerve $(28.8 \%)$ during oral surgery procedures [12]. According to the degree of injury, the altered sensation usually ranges from mild paresthesia to complete anesthesia [13]. Therefore, knowledge of accurate anatomical locations of the MC and mental foramen is an essential factor in the surgical management of any patient [14].

Numerous imaging techniques, including conventional radiographs (intraoral, tomography, panoramic radiographs, cephalometry), and computed tomography (CT) were proposed to localize the MC [15]. However, panoramic radiographs have a great role among them because of their reported benefits [16], and are still being used by the majority of surgeons as the only imaging modality in dental implant assessment [17]. They have been considered for a primary estimation to determine the bone height and implant-mandibular canal distance [18]. It was revealed that without using $\mathrm{CT}$, panoramic radiographs were sufficient for measuring the height of alveolar bone for placement of implants in the mandibular posterior region, and there was little difference from cases that utilized linear or spiral CT [19]. In comparison with $\mathrm{CT}$ and other expensive tests, the panoramic image has a lower cost, rapid, greatly available with low radiation dose. Additionally, if metal prostheses are present, CT may produce streak artifacts. Furthermore, the patient should not move through a lengthy period of CT imaging [20]. However, panoramic radiograph like other methods has its own limitations such as high magnification, lower image clarity, distortion, low image resolution, and two-dimensional information without any sectional data [21, 22].

In implantology, panoramic views are commonly used for diagnostic purposes [23]. They had showed good visualization of the superior border of the $\mathrm{MC}$, and it was convenient for treatment planning of dental implant surgery in the absence of other cross-sectional images (like CT), keeping in mind the dimensional changes and magnification factor [24]. As well, a linear tomogram and/or CT may be used. Although the frequency of application of these imaging techniques has been raised, pre-implant CT is not mandatory in all cases [25]. Even though the necessity for cross-sectional imaging has been intensely recommended, panoramic radiography is considered to be the standard radiographic examination for implant treatment planning since it has low radiation dose and provides valuable radiographic inspection [26, 27].

Although the CT evaluation can provide threedimensional information [28], the cost and radiation dose of the procedure should be considered and outweighed by the value of expected information [29]. Even newly invented CBCT scans have a higher cost and cumulative radiation compared to panoramic radiographs [30]. The present research assesses the reliability of panoramic radiograph, as the only used imaging technique, in determining the $\mathrm{ABH}$ prior to implant placement in the maxillary and mandibular posterior sites as critical areas. It is the first study that specifically estimates the safety of assessment 
with panoramic radiographs in these high-risk regions. In addition to the evaluation of the soundness of implant length estimation (under/over), it also records the associated complications and their influence on the fate of the inserted implants, thus extending the knowledge in literature.

\section{Question in focus}

Panoramic radiographs are still regarded as one of the most widely used imaging modality in implant surgery. This outlines the main goal of this study in answering the following question: is it safe for implantologist to assess the $\mathrm{ABH}$ depending only on panoramic radiographs?

\section{Methods}

\section{Study design}

The investigators planned and implemented a prospective study composed of patients who had undergone an implant surgery with different treatment modalities (conventional, immediate, piezoelectric site preparation, ridge split) at the Implant Unit of Dental Teaching Hospital between January 2010, and December 2016. The implant lengths used in this study (Dentium ${ }^{\circ}$, Implantium $^{\circ}$, Seoul, Korea) were 8, 10, 12, and $14 \mathrm{~mm}$.

Subjects eligible for study inclusion were those who had implants inserted at the maxillary and mandibular posterior regions. Any patient with implants that required to be installed at the anterior regions, implants that did not have any relation with the MS and MC, or radiographs presented with unclear findings were excluded from enrollment.

All the included patients have signed the informed consent regarding their agreement for the implant surgery. The whole study was approved by the institutional review board (Ethics Committee) of the College of Dentistry, University of Baghdad.

\section{Preoperative assessment}

The implants selected for this study were assessed preoperatively and inserted by a single, skilled, and wellexperienced oral and maxillofacial surgeon $(\mathrm{TH})$, while the postoperative evaluation was performed by other surgeon (FJ) to prevent any bias. To obtain a standardized methodology, all of the evaluated panoramic radiographs were requested from the same unit (Carestream Dental, CS 8100 Digital Panoramic System, New York, USA). The preoperative assessment of ABH, taking into consideration the magnification rate, was determined from the alveolar crest to the superior border of the $\mathrm{MC}$ and from the crest of the bone to the inferior border of the MS using digital Vernier Caliper and LED $\mathrm{x}$-ray film viewer. Regarding the $\mathrm{MC}, 2 \mathrm{~mm}$ were subtracted as a safety margin to determine the length of implant to be inserted.

\section{Postoperative assessment}

After implants insertion, this level ( $2 \mathrm{~mm}$ from $\mathrm{MC}$ ) was considered as a zero point from which the measurements were referred as either underestimated (positive value that was distant to $2 \mathrm{~mm}$ from the $\mathrm{MC}$ ) or overestimated (negative value that was closer than $2 \mathrm{~mm}$ to the $\mathrm{MC})$. Concerning the upper posterior region, the floor of the MS represented the borderline between underestimation (positive value that was distant to the floor of the MS) and overestimation (negative value that was inside the MS). The estimation (under/over) was determined depending on the distance measured from the apical end of implant to the floor of the MS and the roof of the MC using KODAK $95003^{\circ} \mathrm{D}^{\circ} \mathrm{CBCT}$ (Carestream Health, Inc., Marne-la-Vallée, France). All patients were followed-up in the first year following implants insertion for any abnormal sign and/or symptom. Any complication associated with overestimated implants (inside the sinus or closer than $2 \mathrm{~mm}$ from the $\mathrm{MC}$ ) was assessed and recorded. The validity of surgeon's decision was depended on the amount of $\mathrm{ABH}$ in underestimated sites $(<2 \mathrm{~mm} / \geq 2 \mathrm{~mm})$, the percentage of overestimated implants insertion (low/high), and the adverse influence of reported complications (transient complications: ecchymosis, hematoma, hemorrhage, temporary paresthesia; permanent complication: persistent anesthesia).

\section{Statistical analysis}

Statistical package of social science program (SPSS version 24 for Windows, SPSS Inc., Chicago, IL, USA) was used to analyze the data. Descriptive statistics (mean, range, frequency, minimum, maximum, percentage) and standard deviations (SD) were computed for each study variable. The independent sample T-test was used to determine whether there is a statistically significant difference between the means in two groups. Two proportions Z-test was utilized to compare the measured variables between maxilla and mandible in overestimated sites. The significance level was considered at $P$-value $\leq 0.05$.

\section{Results}

Eighty patients were available to be enrolled. Seven of them were excluded due to unclear anatomical findings of their panoramic radiographs. As a result, 73 patients ( 21 males and 52 females) with age ranged between 18 and 65 years (mean age $=42.1$ ) were included in this study. A detailed description of the study sample including the total number of used implants with their lengths is presented in Table 1 .

The findings of postoperative $\mathrm{CBCT}$ scans showed underestimation in 138 sites (93.2\%); there was a highly significant difference between overestimation $(10$ sites; $6.8 \%)$ and underestimated readings $(P<0.01$; Table 2). 
Table 1 Summary of study variables for the entire sample

\begin{tabular}{ll}
\hline Study variable & Descriptive statistics N (\%) \\
\hline Sample size (implants): & $148(100)$ \\
Posterior maxilla & $68(45.9)$ \\
Posterior mandible & $80(54.1)$ \\
Implant length $(\mathrm{mm}):$ & \\
8 & $32(21.6)$ \\
10 & $61(41.2)$ \\
12 & $52(35.1)$ \\
14 & $3(2.1)$ \\
\hline
\end{tabular}

$\mathrm{N}$, number of occurrences

Regarding underestimation, the results showed nonsignificant difference $(P=0.256)$ between posterior maxilla $($ mean $=1.72 \pm 1.5)$ and posterior mandible (mean = $1.45 \pm 1.37$ ). The ABH was $<2 \mathrm{~mm}$ in 102 sites (73.9\%) of the underestimated distances, and they were significantly $(P<0.01)$ more than sites with $\mathrm{ABH} \geq 2 \mathrm{~mm}$ (26.1\%). The ranges of $\mathrm{ABH}$ in relation to different sites of underestimated implants are shown in Table 3.

The overestimated implants were recorded at 1 site in the posterior maxilla and 9 sites in posterior mandible. Statistically, there was a highly significant difference $(P=0.00034)$ between the two regions. A detailed statistics of overestimated implants regarding the jaws and sites in relation to implant lengths are presented in Table 4.

The reported complications revealed 5 cases with transient paresthesia, ranged 5 to 21 days, in the mandibular overestimated implants. Inferior alveolar nerve injury (direct trauma from implant) was not reported in this study.

\section{Discussion}

In order to insert an implant with further length, we need at least $2 \mathrm{~mm}$ of $\mathrm{ABH}$ as the length of the used implant system is increased by $2 \mathrm{~mm}$ for each successive unit (Table 1). In the present study, the majority of measurements (93.2\%) were underestimated with a nonstatistically significant difference between posterior maxilla and mandible $(P>0.05)$. They were significantly more than overestimated sites (Table 2). However, this
Table 3 The relation between implant sites and remaining bone height after insertion in underestimated cases

\begin{tabular}{lllll}
\hline $\begin{array}{lllll}\text { Underestimated sites } \\
(N=138)\end{array}$ & & \multicolumn{2}{l}{ ABH N (\% within implant site) } & Total \\
\cline { 2 - 4 } & & $<2 \mathrm{~mm}$ & $\geq 2 \mathrm{~mm}$ & \\
\hline Posterior maxilla & $\mathbf{P}$ & $7(63.6)$ & $4(36.4)$ & $\mathbf{1 1}$ \\
& $\mathbf{2 P}$ & $18(69.2)$ & $8(30.8)$ & $\mathbf{2 6}$ \\
& $\mathbf{1 M}$ & $19(86.4)$ & $3(13.6)$ & $\mathbf{2 2}$ \\
& $\mathbf{2 M}$ & $6(75)$ & $2(25)$ & $\mathbf{8}$ \\
Posterior mandible & $\mathbf{1 P}$ & $3(75)$ & $1(25)$ & $\mathbf{4}$ \\
& $\mathbf{2 P}$ & $10(71.4)$ & $4(28.6)$ & $\mathbf{1 4}$ \\
& $\mathbf{1 M}$ & $28(70)$ & $12(30)$ & $\mathbf{4 0}$ \\
& $\mathbf{2 M}$ & $11(84.6)$ & $2(15.4)$ & $\mathbf{1 3}$ \\
Total & & $\mathbf{1 0 2}$ & $\mathbf{3 6}$ & $\mathbf{1 3 8}$ \\
\hline
\end{tabular}

$A B H$ Available bone height after implants insertion

high percentage of underestimation did not mean a high percentage of short implants, where the $\mathrm{ABH}$ in most of the underestimated sites $(73.9 \%)$ was less than $2 \mathrm{~mm}$. As a result, no additional length of dental implant can be used. Akdeniz et al. [31] compared bone height and density measurements of implant recipient sites by panoramic radiography and computed tomography. Their results suggested that panoramic radiography significantly underestimated the bone height compared with CT. Another study conducted by Zarch et al. [16], which aimed to evaluate the accuracy of panoramic radiography in linear measurements of the jaws, showed underestimation in $83 \%$ of the measurements. These findings were consistent with the outcomes of this study. Our results contrast those of Fortin et al. [32] and others [33, 34] who concluded that distances were overestimated on the panoramic radiographs.

In both posterior regions, most of the underestimated sites presented with available bone (after insertion) of less than $2 \mathrm{~mm}$ (Table 3). Regarding maxilla, the most reliable choice of implant length was at the $1 \mathrm{M}$ sites (86.4\%), followed by the $2 \mathrm{M}(75 \%)$, then the $2 \mathrm{P}(69.2 \%)$, and finally the $1 \mathrm{P}(63.6 \%)$. However, the mandibular posterior region showed different results from the maxilla where the $2 \mathrm{M}$ sites were the most reliable one (84.6\%), followed by $1 \mathrm{P}(75 \%)$, then the $2 \mathrm{P}(71.4 \%)$, and

Table 2 Descriptive statistics for the outcome variables

\begin{tabular}{|c|c|c|c|c|c|c|c|}
\hline Variable & $\mathrm{N}$ & Premolars & Molars & Minimum (mm) & Maximum (mm) & Mean \pm SD & $P$ value \\
\hline Underestimated sites: & 138 & 55 & 83 & 0.2 & 6 & $1.58 \pm 1.43$ & $0.008^{\mathrm{a}_{1}^{* * *}}$ \\
\hline $\begin{array}{l}\text { Posterior maxilla } \\
\text { Posterior mandible }\end{array}$ & $\begin{array}{l}67 \\
71\end{array}$ & $\begin{array}{l}37 \\
18\end{array}$ & $\begin{array}{l}30 \\
53\end{array}$ & & & & \\
\hline Overestimated sites: & 10 & 3 & 7 & -0.2 & -1.6 & $0.36 \pm 0.44$ & \\
\hline $\begin{array}{l}\text { Posterior maxilla } \\
\text { Posterior mandible }\end{array}$ & $\begin{array}{l}1 \\
9\end{array}$ & $\begin{array}{l}1 \\
2\end{array}$ & $\begin{array}{l}0 \\
7\end{array}$ & & & & \\
\hline
\end{tabular}

${ }^{\mathrm{a} B y}$ T-test (2-tailed)

*** Highly significant 
Table 4 The percentages of different types of implant length that had caused overestimation

\begin{tabular}{llllll}
\hline Implant length $(\mathrm{mm})$ & Jaw & Site & $\begin{array}{l}\text { Amount of } \\
\text { overestimation }(\mathrm{mm})\end{array}$ & $\begin{array}{l}\mathrm{N} \text { of } \\
\text { total }\end{array}$ \\
\hline 8 & Mandible & 1M & -0.2 & 1 & 0.7 \\
8 & Mandible & $1 \mathrm{M}$ & -1.6 & 1 & 0.7 \\
8 & Mandible & $2 \mathrm{M}$ & -0.2 & 3 & 2 \\
8 & Mandible & $2 \mathrm{P}$ & -0.2 & 1 & 0.7 \\
10 & Maxilla & $2 \mathrm{P}$ & -0.4 & 1 & 0.7 \\
10 & Mandible & 1P & -0.2 & 1 & 0.7 \\
12 & Mandible & $2 \mathrm{M}$ & -0.2 & 2 & 1.3 \\
Total & & & & $\mathbf{1 0}$ & $\mathbf{6 . 8}$ \\
\hline
\end{tabular}

the $1 \mathrm{M}(70 \%)$. Therefore, a proper attention should be given for the least reliable sites in a specific region.

Ten implants with overestimation were recorded in our study; there was an important difference between posterior maxilla and mandible $(P<0.01)$. The higher percentage was at the mandibular posterior region ( 9 sites) with just 1 site at the posterior maxilla presented at the $2 \mathrm{P}$ site (Table 4). Interestingly, the mandibular $2 \mathrm{M}$ had more tendency for overestimation (5 out of 9 sites), followed by the mandibular 1M (2 out of 9 sites), while both mandibular premolars (1P and $2 \mathrm{P})$ had an equal existence ( 1 site for each). Therefore, the risk of IAN injury is more expected to occur at the $2 \mathrm{M}$ area. These results are in agreement with those of Lin et al. [11] who concluded that mandibular $2 \mathrm{M}$ presented highest risk for IAN injury (3.82 times) than other tooth type.

Little evidences existed concerning the minimum safe distance to guard the IAN during bone drilling; there was an obvious controversy about this subject. Sammartino et al. [35] suggested a distance of $1 \mathrm{~mm}$ between the implant and mandibular canal to prevent damage to the underlying nerve. For clinical safety, the authors recommended an additional $0.5 \mathrm{~mm}$ as a cushion. Accordingly, a $1.5 \mathrm{~mm}$ of minimal distance should be planned to avoid potential nerve injury. Hartmann et al. [36] concluded that sensory disturbances of the IAN could be avoided by keeping an average safety zone of $2.65 \mathrm{~mm}$ between implant and nerve. The results of our study showed that even when implants are inserted closer than $2 \mathrm{~mm}$ to the IAN (Table 4), there was no any permanent damage to the nerve as all of the reported complications (5 cases of paresthesia) were transient and cured spontaneously without any intervention. These results were in accordance with Tufekcioglu et al. [37] who suggested that if the operator can avoid thermal, pressure, and traumatic damage to the IAN, the implants can be placed closer than $2 \mathrm{~mm}$ to the inferior alveolar canal. Furthermore, the authors concluded that when $2 \mathrm{~mm}$ was considered as a safety level, the distance from implants to the IAC did not yield any statistical difference regarding postoperative neurosensory complications.

\section{Conclusions}

Regarding posterior regions of the jaws, there is a tendency toward underestimation in panoramic radiographs, which is better than overestimation. Measurements at the maxillary $1 \mathrm{M}$ and $2 \mathrm{M}$ sites were more often underestimated by less than $2 \mathrm{~mm}$ than the measurements of the maxillary $1 \mathrm{P}$ and $2 \mathrm{P}$ sites. Measurements of the mandibu$\operatorname{lar} 2 \mathrm{M}$ site were more often underestimated by less than $2 \mathrm{~mm}$ than measurements of the other mandibular sites. Maxillary $1 \mathrm{P}$ and mandibular $1 \mathrm{M}$ sites presented the highest rate of underestimated measurements of $\geq 2 \mathrm{~mm}$ than the other sites. Overestimated measurements were more often seen in the mandible in comparison to the maxilla. Moreover, implants inserted closer than $2 \mathrm{~mm}$ to the inferior alveolar canal did not cause any permanent damage or injury to the IAN.

\section{Abbreviations}

MS: Maxillary sinus; MC: Mandibular canal; 1P: First premolars; 2P: Second premolars; 1M: First molars; 2M: Second molars; ABH: Available bone height; CBCT: Cone beam computed tomography; IAN: Inferior alveolar nerve; IAC: Inferior alveolar canal; CT: Computed tomography; SD: Standard deviations; N: Number

\section{Acknowledgments}

We would like to greatly thank Nidhal Shapoo and Layla Ismael, assistant nurses at dental implant unit of the Oral and Maxillofacial Surgery

Department, for their kind care and outmost assistance.

\section{Authors' contributions}

JM contributed to the concept and design of the study. TH performed the preoperative assessment and surgical procedures. FJ achieved the postoperative assessment, patient's follow-up, data collection, and was a major contributor in writing the manuscript. MR analyzed the data of patients and interpreted the results. All authors participated in the discussion of outcomes and final revision of the manuscript. All of them read and approved the final manuscript.

\section{Funding}

This study did not receive funding from any organization.

Availability of data and materials

The datasets used and/or analyzed during the current study are available from the corresponding author on reasonable request.

\section{Ethics approval and consent to participate}

This study was approved by the Ethics Committee of the College of Dentistry, University of Baghdad. A written informed consent was obtained from each patient to participate in this study.

Consent for publication

Not applicable.

\section{Competing interests}

All authors (Firas A. Jamil, Jamal A. Mohammed, Thair A. Hasan, Mohammed G. Rzoqi) state that there are no conflicts of interest.

\section{Author details}

'Department of Oral \& Maxillofacial Surgery, Dental Teaching Hospital, College of Dentistry, University of Baghdad, Bab-Almoadham, P.O.Box 1417, Baghdad, Iraq. ${ }^{2}$ Department of Biomedical Applications, Institute of Laser for Postgraduate Studies, University of Baghdad, Baghdad, Iraq. 
Received: 15 October 2019 Accepted: 27 March 2020

Published online: 06 April 2020

\section{References}

1. Greenstein G, Cavallaro J, Romanos G, Tarnow D. Clinical recommendations for avoiding and managing surgical complications associated with implant dentistry: a review. J Periodontol. 2008;79:1317-29.

2. Chan HL, Brooks SL, Fu JH, Yeh CY, Rudek I, Wang HL. Cross-sectional analysis of the mandibular lingual concavity using cone beam computed tomography. Clin Oral Implants Res. 2011;22:201-6.

3. Annibali S, Ripari M, La Monaca G, Tonoli F, Cristalli MP. Local accidents in dental implant surgery: prevention and treatment. Int J Periodontics Restorative Dent. 2009:29:325-31.

4. Chrcanovic B, Albrektsson T, Wennerberg A. Reasons for failures of oral implants. J Oral Rehabil. 2014:41:443-76.

5. Shibli JA, Martins MC, Loffredo LC, Scaf G. Detection of the mandibular canal and the mental foramen in panoramic radiographs: intraexaminer agreement. J Oral Implantol. 2012;38:27-31.

6. Raghoebar GM, Vissink A. Treatment for an endosseous implant migrated into the maxillary sinus not causing maxillary sinusitis: case report. Int J Oral Maxillofac Implants. 2003;18:745-9.

7. Juodzbalys G, Wang HL, Sabalys G, Sidlauskas A, Galindo-Moreno P. Inferior alveolar nerve injury associated with implant surgery. Clin Oral Implants Res. 2013:24:183-90.

8. Ramos B. Immediate implant placement in the posterior mandible: a cone beam computed tomography study. Quintessence Int. 2016:47:505-14.

9. Georgescu CE, Rusu MC, Sandulescu M, Enache AM, Didilescu AC. Quantitative and qualitative bone analysis in the maxillary lateral region. Surg Radiol Anat. 2012;34:551-8.

10. Demircan S, Cankaya AB. Is immediate implant placement possible in the maxillary molar area? An anatomical study. Quintessence Int. 2016;47:853-9.

11. Lin M-H, Mau L-P, Cochran DL, Shieh Y-S, Huang P-H, Huang R-Y. Risk assessment of inferior alveolar nerve injury for immediate implant placement in the posterior mandible: a virtual implant placement study. J Dent. 2014;42:263-70.

12. Tay A, Zuniga JR. Clinical characteristics of trigeminal nerve injury referrals to a university Centre. Int J Oral Maxillofac Surg. 2007;36:922-7.

13. Alhassani AA, AIGhamdi AST. Inferior alveolar nerve injury in implant dentistry: diagnosis, causes, prevention, and management. J Oral Implantol. 2010;36:401-7.

14. Soheilifar S, Bidgoli M, Shokri A, Faradmal J, Kafilzadeh S, Eyvazi P, Nikkhah M. Panoramic radiographic study of mandibular canal and mental foramen in a selected Iranian population. SRM J Res Dent Sci. 2016:7:209-13.

15. Vazquez L, Saulacic N, Belser U, Bernard JP. Efficacy of panoramic radiographs in the preoperative planning of posterior mandibular implants: a prospective clinical study of 1527 consecutively treated patients. Clin Oral Implants Res. 2008;19:81-5.

16. Zarch SH, Bagherpour A, Langaroodi AJ, Yazdi AA, Safaei A. Evaluation of the accuracy of panoramic radiography in linear measurements of the jaws. Iran J Radiol. 2011;8:97-102.

17. Sakakura C, Morais J, Loffredo L, Scaf G. A survey of radiographic prescription in dental implant assessment. Dentomaxillofac Radiol. 2003;32: 397-400.

18. Kütük N, Gönen ZB, Yasar MT, Demirbas AE, Alkan A. Reliability of panoramic radiography in determination of neurosensory disturbances related to dental implant placement in posterior mandible. Implant Dent. 2014;23: 648-52.

19. Frei C, Buser D, Dula K. Study on the necessity for cross-section imaging of the posterior mandible for treatment planning of standard cases in implant dentistry. Clin Oral Implants Res. 2004;15:490-7.

20. Barrett JF, Keat N. Artifacts in CT: recognition and avoidance. Radiographics. 2004:24:1679-91.

21. Wakoh M, Harada T, Otonari T, Otonari-Yamamoto M, Ohkubo M, Kousuge Y, Kobayashi N, Mizuta S, Kitagawa H, Sano T. Reliability of linear distance measurement for dental implant length with standardized periapical radiographs. Bull Tokyo Dent Coll. 2006:47:105-15.

22. Peker I, Alkurt MT, Mihcioglu T. The use of 3 different imaging methods for the localization of the mandibular canal in dental implant planning. Int J Oral Maxillofac Implants. 2008;23:463-70.
23. Dula K, Mini R, van der Stelt PF, Buser D. The radiographic assessment of implant patients: decision-making criteria. Int J Oral Maxillofac Implants. 2001;16:80-9.

24. Bakry AM, Alzarea BK. Validity of digital panoramic radiography in detection of the Mandibular Canal in implant cases. Indian J Stomatol. 2016;7:1-3.

25. Kim Y, Park J, Kim S, Kim J, Kim J. Magnification rate of digital panoramic radiographs and its effectiveness for pre-operative assessment of dental implants. Dentomaxillofac Radiol. 2011;40:76-83.

26. Harris D, Buser D, Dula K, Gröndahl K, Harris D, Jacobs R, Lekholm U, Nakielny R, Van Steenberghe D, Van Der Stelt P. EAO guidelines for the use of diagnostic imaging in implant dentistry: a consensus workshop organized by the European Association for Osseointegration in Trinity College Dublin. Clin Oral Implants Res. 2002;13:566-70.

27. Harris D, Horner K, Gröndahl K, Jacobs R, Helmrot E, Benic Gl, Bornstein MM, Dawood A, Quirynen M. EAO guidelines for the use of diagnostic imaging in implant dentistry 2011. A consensus workshop organized by the European Association for Osseointegration at the Medical University of Warsaw. Clin Oral Implants Res. 2012;23:1243-53.

28. Hagiwara $Y$, Koizumi M, Igarashi T. Application of $C T$ imaging for dental implant simulation. J Oral Sci. 1999:41:157-61.

29. Frederiksen NL. Diagnostic imaging in dental implantology. Oral Surg Oral Med Oral Pathol Oral Radiol Endod. 1995:80:540-54.

30. Li G. Patient radiation dose and protection from cone-beam computed tomography. Imaging Sci Dent. 2013:43:63-9.

31. Akdeniz BG, Okşan T, Kovanlikaya I, Genç I. Evaluation of bone height and bone density by computed tomography and panoramic radiography for implant recipient sites. J Oral Implantol. 2000;26:114-9.

32. Fortin $\mathrm{T}$, Camby E, Alik M, Isidori M, Bouchet $\mathrm{H}$. Panoramic images versus three-dimensional planning software for oral implant planning in atrophied posterior maxillary: a clinical radiological study. Clin Implant Dent Relat Res. 2013;15:198-204.

33. Serhal CB, Jacobs R, Flygare $L$, Quirynen M, van Steenberghe D. Perioperative validation of localisation of the mental foramen. Dentomaxillofac Radiol. 2002;31:39-43.

34. Rockenbach MIB, Sampaio MCC, LJd C, NPd C. Evaluation of mandibular implant sites: correlation between panoramic and linear tomography. Braz Dent J. 2003:14:209-13.

35. Sammartino G, Wang HL, Citarella R, Lepore M, Marenzi G. Analysis of occlusal stresses transmitted to the inferior alveolar nerve by multiple threaded implants. J Periodontol. 2013;84:1655-61.

36. Hartmann A, Welte-Jzyk C, Seiler M, Daubländer M. Neurophysiological changes associated with implant placement. Clin Oral Implants Res. 2017;28: 576-81.

37. Tufekcioglu S, Delilbasi C, Gurler G, Dilaver E, Ozer N. Is 2 mm a safe distance from the inferior alveolar canal to avoid neurosensory complications in implant surgery? Niger J Clin Pract. 2017:20:274-7.

\section{Publisher's Note}

Springer Nature remains neutral with regard to jurisdictional claims in published maps and institutional affiliations.

Ready to submit your research? Choose BMC and benefit from:

- fast, convenient online submission

- thorough peer review by experienced researchers in your field

- rapid publication on acceptance

- support for research data, including large and complex data types

- gold Open Access which fosters wider collaboration and increased citations

- maximum visibility for your research: over $100 \mathrm{M}$ website views per year

At BMC, research is always in progress.

Learn more biomedcentral.com/submissions 